CLARISSA MAÇANEIRO VIANA

\title{
A FLEXIBILIZAÇÃO DA JORNADA PERANTE OS TRIBUNAIS E A PRECARIZAÇÃO DO TRABALHO
}

\author{
Dissertação de Mestrado
}

Orientador: Professor Doutor Ronaldo Lima dos Santos

UNIVERSIDADE DE SÃO PAULO

FACULDADE DE DIREITO

São Paulo-SP

2019 


\section{A FLEXIBILIZAÇÃO DA JORNADA PERANTE OS TRIBUNAIS E A PRECARIZAÇÃO DO TRABALHO}

Dissertação apresentada à Banca Examinadora do Programa de Pós-Graduação em Direito, da Faculdade de Direito da Universidade de São Paulo, como exigência parcial para obtenção do título de Mestra em Direito, na área de concentração Direito do Trabalho e da Seguridade Social, sob orientação do Professor Doutor Ronaldo Lima dos Santos.

UNIVERSIDADE DE SÃO PAULO

FACULDADE DE DIREITO

São Paulo-SP

2019 
Autorizo a reprodução e divulgação total e parcial deste trabalho, por qualquer meio convencional ou eletrônico, para fins de estudo e pesquisa, desde que citada a fonte.

Catalogação da Publicação

Serviço de Biblioteca e Digitalização

Faculdade de Direito da Universidade de São Paulo

VIANA, Clarissa Maçaneiro

A flexibilização da jornada perante os tribunais e a precarização do trabalho / Clarissa Maçaneiro Viana; orientador Ronaldo Lima dos Santos - São Paulo, 2019. $186 \mathrm{p}$.

Dissertação (Mestrado - Programa de Pós-Graduação em Direito do Trabalho e Seguridade Social) - Faculdade de Direito, Universidade de São Paulo, 2019.

1. Flexibilização da jornada de trabalho; 2. Jurisprudência trabalhista; 3. Precarização do trabalho. 


\section{AGRADECIMENTOS}

À minha família, sempre em primeiro lugar, por ser a melhor que eu poderia ter e nunca me deixar desistir, independentemente das pedras no caminho.

Ao meu orientador, Professor Ronaldo Lima dos Santos, pela oportunidade oferecida e dedicação prestada, bem como aos professores Flávio Roberto Batista e Paula Marcelino, pelos valiosos debates em sala de aula e necessárias correções na qualificação.

Aos meus amigos e amigas, sempre tão presentes, por nunca terem me negado hospedagem, opinião acadêmica e cerveja. Eliz, Marina, David, Bernardo, Mathias, Eduardo, Gabriel, Luccas, Lawrence, Dani, Constance, Amanda, Mari, Thiago, Bruno e tantos, tantos outros.

Ao Nuredin Allan \& demais membros do escritório, pelo apoio e suporte dado para a realização desta empreitada, majoritariamente interestatal, a despeito das minhas constantes viagens e ausências.

A todos que estão ao meu lado na luta por uma sociedade mais justa e livre da opressão. Nossos fracassos são nossas vitórias. 
O trem atrasou (1941)

Composição: Paquito, Estanislau Silva e Arthur Vilarinho.

Patrão, o trem atrasou

Por isso estou chegando agora

Trago aqui um memorando da Central

$\mathrm{O}$ trem atrasou, meia hora

O senhor não tem razão

Pra me mandar embora!

O senhor tem paciência

É preciso compreender

Sempre fui obediente

Reconheço o meu dever

Um atraso é muito justo

Quando há explicação

Sou um chefe de família

Preciso ganhar meu pão

E eu tenho razão. 


\section{RESUMO}

VIANA, Clarissa Maçaneiro. A flexibilização da jornada perante os Tribunais e a precarização do trabalho. 2019. 186 p. Mestrado - Faculdade de Direito, Universidade de São Paulo, São Paulo, 2019.

A limitação à jornada de trabalho no Brasil, no decorrer de sua história recente, sofreu inúmeras alterações por meio de leis e medidas provisórias, sendo permanentemente marcada por uma regulação flexível, que têm se acentuado no período de predominância do capital financeiro. Para além dos textos legais, a jurisprudência nesse ramo do direito possui destacada importância, vez que aborda temas não abrangidos pela legislação em vigor, especificando os meandros de sua aplicação e, inclusive, criando novas figuras por ela não contempladas. Nessa seara, o presente estudo intenta averiguar qual o papel desempenhado pela jurisprudência sumulada do Supremo Tribunal Federal e Tribunal Superior do Trabalho sobre a flexibilização da jornada, com foco em quatro institutos, eleitos pela frequência com que são abordados nos contratos de trabalho e nos textos sumulares: a compensação semanal, a compensação anual (banco de horas), os turnos ininterruptos de revezamento e a jornada 12×36. A partir da leitura das alterações procedidas, debates travados e argumentações utilizadas para justificar as respectivas posições, busca-se auferir se a jurisprudência atuou de forma a facilitar a ampliação da flexibilização da jornada no país ou se criou obstáculos à sua implementação, bem como qual o diálogo estabelecido pelos Tribunais com as leis, decretos e medidas provisórias implementadas sobre o tema.

Palavras-chave: flexibilização da jornada de trabalho, jurisprudência trabalhista, precarização do trabalho. 


\begin{abstract}
VIANA, Clarissa Maçaneiro. 2019. The flexibilization of working hours in court decisions and the precarious work. 186 p. Mestrado - Faculdade de Direito, Universidade de São Paulo, São Paulo, 2019.

The limitation of working hours in Brazil, in the course of its recent history, has went through numerous legal changes, being permanently marked by a flexible regulation, witch have been accentuated in the contemporary capitalismo, marked by the process of "financialization". In addition to the legal texts, the jurisprudence in labor law has a prominent importance, since it addresses issues not covered by the current legislation, specifying the intricacies of its application and, even creating new figures. Thus, the present study seeks to ascertain the role played by the case laws summated by the Federal Supreme Court and Superior Labor Court on the flexibilization of working hours, focusing on four institutes, elected by the frequency with which they are approached in labor contracts and courts decisions: weekly compensation, annual compensation ("hour bank"), uninterrupted shifts and 12x36 shift. Based on the analysis of the changes made, discussions and arguments used to justify their positions, we sought to determine whether the case laws have acted in a way that facilitates the extension of the working time flexibilization or if they created obstacles to its implementation, as well as the dialogue established by the Courts with the laws, decrees and provisional measures implemented on the subject.
\end{abstract}

Key words: working hours flexibilization, labor jurisprudence, precarious work. 


\section{LISTA DE ABREVIAÇÕES E SIGLAS}

CESIT - Centro de Estudos Sindicais e Economia do Trabalho

CLT - Consolidação das Leis do Trabalho

CNAE - Cadastro Nacional de Atividades Econômicas

CNJ - Conselho Nacional de Justiça

CTPS - Carteira de Trabalho e Previdência Social

DIEESE - Departamento Intersindical de Estatística e Estudos Socioeconômicos

FGTS - Fundo de Garantia por Tempo de Serviço

FMI - Fundo Monetário Internacional

IBGE - Instituto Brasileiro de Geografia e Estatística

MP - Medida Provisória

MTE - Ministério do Trabalho e Emprego (atualmente denominado somente Ministério do Trabalho)

NR - Norma Regulamentadora

OIT - Organização Internacional do Trabalho

OJ - Orientação Jurisprudencial

PLR - Participação em Lucros e Resultados

PNAD - Pesquisa Nacional por Amostra de Domicílios

RAIS - Relação Anual de Informações Sociais

SBDI - Subseção de Dissídios Individuais

STF - Supremo Tribunal Federal

TRT - Tribunal Regional do Trabalho

TST - Tribunal Superior do Trabalho 


\section{SUMÁRIO DE QUADROS E TABELAS}

Gráfico 1: Evolução da jornada de trabalho (grupos de horas habitualmente trabalhadas por semana em todos os trabalhos) .78

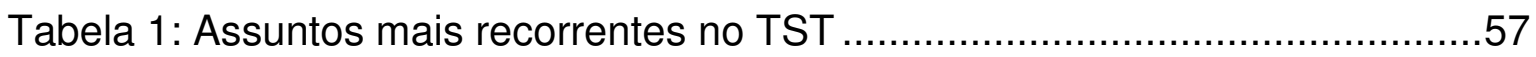

Tabela 2: Alterações jurisprudenciais sobre a compensação semanal...............103

Tabela 3: Alterações jurisprudenciais sobre o banco de horas ...........................112

Tabela 4: Alterações jurisprudenciais sobre a escala 12×36 ...........................121

Tabela 5: Alterações jurisprudenciais sobre os turnos ininterruptos de revezamento 132 


\section{SUMÁRIO}

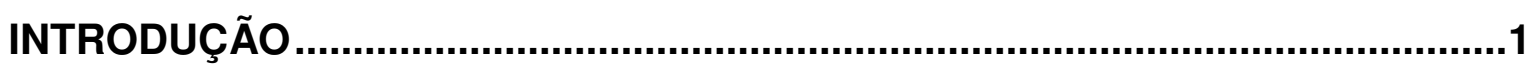

1. A REGULAMENTAÇÃO DA JORNADA DE TRABALHO NO BRASIL .............8

1.1. As primeiras leis sobre a jornada e a criação da CLT .................................

1.2. As primeiras ondas de flexibilização e a Constituição de 1988 ......................18

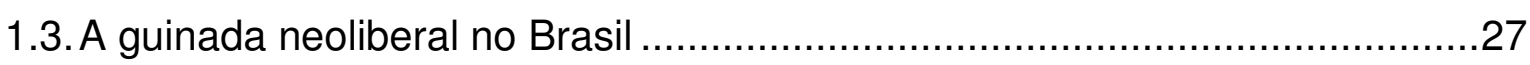

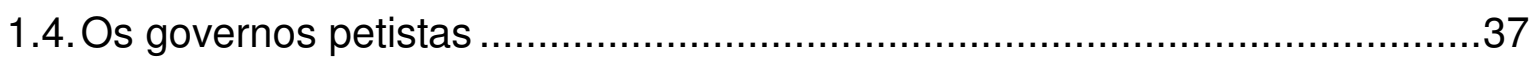

2. O DIREITO E A FLEXIBILIDADE DOS TEMPOS DE TRABALHO .................45

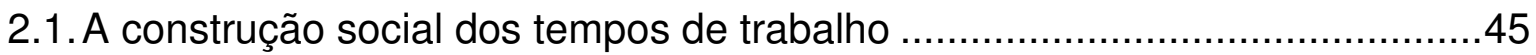

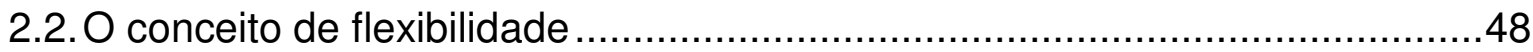

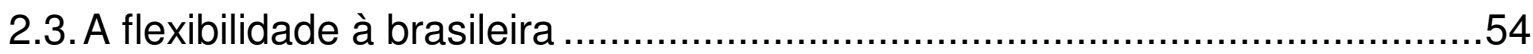

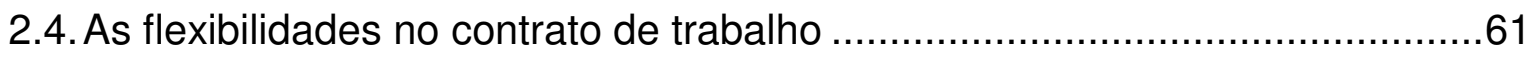

2.4.1. Flexibilidade de formas de contratação .................................................61

2.4.2. Flexibilidade de remuneração.............................................................

2.4.3. Flexibilidade de funções ......................................................................

2.4.4. Flexibilidade de jornada...................................................................

2.5. A flexibilização nas negociações coletivas .................................................79

3. A FLEXIBILIZAÇÃO DA JORNADA NA JURISPRUDÊNCIA .........................83

3.1. O papel da jurisprudência no direito trabalhista......................................... 83

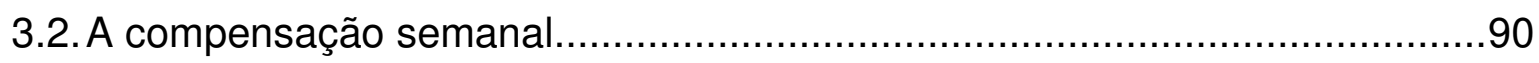

3.3. Compensação anual (Lei $\left.n^{\circ} 9.601 / 98\right)$.................................................104

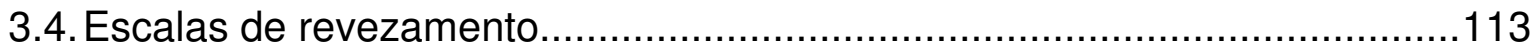

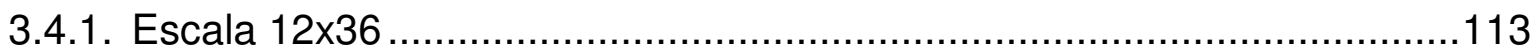

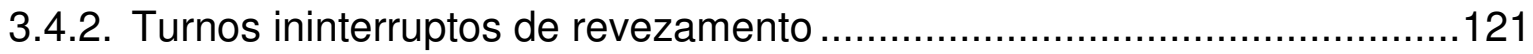

3.5. Síntese da atuação da jurisprudência na flexibilização da jornada................133

4. A LEI N 13.467/2017 E A DESCONSTRUÇÃO JUSTRABALHISTA............145

4.1. A reforma trabalhista e o retorno ao direito neoliberal ................................145

4.2. As alterações relativas à jornada e os conflitos com a jurisprudência .........155

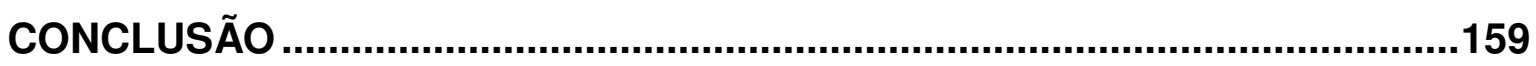

REFERÊNCIA BIBLIOGRÁFICA ........................................................163 


\section{INTRODUÇÃO}

A jornada de trabalho consistiu um dos primeiros temas a serem regulamentados pelo Direito no que tange às relações empregatícias no Brasil. A luta pela jornada de 8 horas diárias obteve grande importância na pauta de reivindicações do movimento operário no Brasil e no mundo, tendo sido, inclusive, objeto da primeira Convenção editada pela Organização Internacional do Trabalho. Ela foi estabelecida no país por legislação esparsa no início do século XX e, em 1943, reprisada na Consolidação das Leis do Trabalho, enquanto a jornada máxima semanal de 44 horas, por sua vez, foi implementada com a Constituição Federal de 1988.

A despeito de tais limitações, a possibilidade de flexibilização da jornada ou seja, a possibilidade de elastecimento rotineiro para além dos limites estabelecidos sem o correspondente pagamento da hora acompanhada do respectivo adicional - tem cada vez mais se ampliado. A CLT, desde sua compilação, já previa como exceção à regra da jornada máxima os vendedores pracistas, funções de serviço externo, os vigias (para os quais o limite era de 10 horas diárias), os gerentes e os empregados nos serviços de estiva. A redação foi alterada por leis posteriores, porém permanece existindo. Ainda, o seu artigo 59 previa a possibilidade de realização de horas suplementares não excedentes a duas horas diárias.

Além da previsão celetária, outras normas foram criadas com a finalidade de flexibilizar a jornada, a exemplo do banco de horas, modalidade de compensação de jornada criada em 1998, então condicionada à negociação coletiva, que dispensa o pagamento imediato das horas extraordinárias caso compensadas dentro de um determinado período de tempo não superior a um ano. A própria Constituição Federal de 1988, muito embora traga os limites de 8 horas diárias e 44 horas semanais, também faz menção à possibilidade compensação de jornada e de redução (tanto de salário como de jornada) através de negociação coletiva.

De acordo com levantamentos do Tribunal Superior do Trabalho (TST), as horas extras figuram todos os anos como o tema mais frequente nos processos em trâmite na Justiça do Trabalho. De tal sorte, para além dos instrumentos legais, a jurisprudência, por meio principalmente de Orientações Jurisprudenciais (OJs) e 
Súmulas, cumpre um também papel fundamental no processo de implementação dessas modalidades, adequando aos casos concretos 0 texto da lei $e$ regulamentando formas de flexibilização à margem dela. Ainda, parte significativa das disposições sobre a jornada que são aplicadas nas lides trabalhistas somente encontra previsão nos textos sumulares, como no caso das jornadas em regime 12x36, que, até a aprovação da Lei $n^{\circ} 13.467 / 2017$, sequer eram mencionadas na CLT ou Constituição Federal. Assim, entender a flexibilização da jornada perante o direito do trabalho no Brasil impende uma análise não somente dos textos de lei aprovados, mas também dos textos sumulados sobre o tema, aqui considerados fontes formais de direito.

O problema sob o qual a presente pesquisa se debruça consiste em compreender as movimentações feitas pela jurisprudência trabalhista no tocante à flexibilização da jornada no Brasil, ou seja, se ela contribuiu para o seu avanço ou se ela criou empecilhos à sua aplicação. Ainda, analisar-se-á qual a relação entre a jurisprudência sumulada e as leis sobre a jornada, de modo a avaliar se há um diálogo entre os dois institutos, ou seja, se a legislação assenta uma posição já consolidada na jurisprudência ou se ela a confronta.

A limitação da jornada de 8 horas diárias e 44 horas semanais, ainda que não tenha sido revogada, sofreu inúmeras relativizações ao longo dos anos. Trabalhamos, assim, com a hipótese de que as interpretações conferidas aos dispositivos da Consolidação das Leis do Trabalho e à Constituição Federal, através de Súmulas, OJs e pelas decisões proferidas nos Tribunais não são uníssonas em sua posição, pois por vezes militam a favor dessa tendência, legitimando o elastecimento reiterado da jornada para além dos limites legalmente estabelecidos, e por vezes atuam de forma a barrar tais retrocessos. Também atuamos com a hipótese de que os textos legais que versam sobre a precarização da jornada usualmente não expressam o entendimento majoritário acerca do tema pela jurisprudência, ou seja, que há um descompasso entre o conteúdo das normas flexibilizadoras e a sua abordagem majoritária pelos Tribunais.

A realização de jornadas extensas pelos trabalhadores é um fator constante na exploração da mão de obra no Brasil, mormente pelo papel que o país desempenha no capitalismo - como já mencionado, mesmo a CLT possui desde sua origem exceções à regra da limitação da carga horária. Todavia, aqui faremos uma análise que passa pela hipótese de que as mais recentes formas de 
flexibilização da jornada de trabalho com vistas a facilitar o seu elastecimento estariam inseridas dentro das demandas do capital financeirizado pela maximização dos lucros através da redução de custos com mão de obra. A ampliação da extração de mais-valia absoluta atenderia aos interesses da burguesia em recuperar as taxas de lucratividade vistas antes da crise iniciada em 1973, necessidade que se mostra cada vez mais imperativa. Assim, a flexibilização da jornada, por mais que não esteja adstrita à atual fase do capitalismo, é por ela utilizada e integra as principais demandas apresentadas pela burguesia para o campo do trabalho na atualidade.

A nova etapa de acumulação capitalista iniciada com 0 processo de financeirização da economia enseja uma reorganização no processo produtivo e na forma de gestão do trabalho e conta com o aumento da jornada como fator essencial para a intensificação das formas de exploração. $O$ avanço tecnológico vem acompanhado da regressão na legislação trabalhista e na precarização das condições de trabalho, dentre as quais localizamos o incentivo e a imposição aos empregados à realização de horas extras cotidianamente, que dificilmente é remunerado em sua totalidade. $O$ discurso neoliberal de uma suposta rigidez da legislação trabalhista, que seria ultrapassada e necessitaria de modernização a fim de possibilitar o enfrentamento pelas empresas à crise econômica e ao desemprego, também integra o cenário de legitimação a essas formas de precarização.

Inobstante, os instrumentos coletivos adquirem importância crucial na medida em que parte significativa das formas de flexibilização da jornada demandam a chancela do sindicato da categoria profissional. As negociações coletivas envolvendo institutos como a implementação do banco de horas, da redução dos intervalos intrajornada e in itinere, dentre outros, é tema recorrente nos debates jurisprudenciais, cuja análise nos permitirá identificar se a tendência é o reconhecimento da autonomia das partes ou o seu afastamento em prol dos limites mínimos estabelecidos em lei.

O objetivo desta pesquisa é, portanto, explorar as formas como a legislação e a jurisprudência trabalhista se relacionam com a flexibilização da jornada de trabalho, principalmente aquelas que implicam em um aumento das horas trabalhadas por dia, e entender de que forma elas se inserem dentro das demandas do capitalismo na atualidade, quais fatores ensejaram sua criação e ampla 
implementação nos contratos de trabalho. Objetiva-se também averiguar se há correlação entre as leis promulgadas com vistas a flexibilizar a jornada e os entendimentos jurisprudenciais existentes à época, ou seja, se a jurisprudência se coloca como fator de facilitação da aplicação de institutos flexibilizadores ou se essa tendência ocorre a par das tendências jurisprudenciais.

O presente estudo tem sua importância na medida em que se tem assistido progressivamente a um aumento nas formas de intensificação do trabalho. A Lei $n^{\circ}$ 13.467/2017, conhecida como 'reforma trabalhista', é a mais gritante expressão de uma tendência que não é novidade: boa parte dos esforços no avanço da precarização do trabalho ao longo dos últimos anos se deram com o foco na jornada de trabalho.

Trata-se de uma realidade de parcela significativa dos contratos de trabalho: desde empregados de pequenas e médias até grandes empresas, homens e mulheres (ainda que de formas distintas), pessoas alocadas em trabalhos intelectuais e manuais - a regra dos contratos de trabalho no país é a ocorrência da flexibilização da jornada. Da mesma maneira, a reforma trabalhista e a sua apresentação como resposta ao atual contexto econômico de crise reacendem o debate sobre a relação entre os processos de retirada de direitos na esfera trabalhista e as demandas do capital.

A realização desta pesquisa justifica-se, portanto, pela necessidade de compreender as previsões jurisprudenciais e os instrumentos legais que implementaram formas de intensificação da jornada como integrantes de um contexto mais amplo de precarização que tem se aprofundado nos últimos anos. Entendemos que a aplicação das normas relativas à jornada pela jurisprudência e o modo como a qual elas são abordadas pela doutrina trazem elementos importantes para a compreensão de como a retirada de direitos com vistas à manutenção dos lucros da classe dominante ocorre na prática dos contratos de trabalho. Trata-se, acima de tudo, de uma das esferas da precarização que atinge mais incisivamente os trabalhadores, pois furta o pouco tempo livre que Ihes resta, dificulta o convívio social e familiar e traz sérias implicações no tocante à segurança no trabalho.

O estudo da jurisprudência possibilita analisar uma das facetas dessa problemática, de modo a dialogar com estudos que pretendem compreender as demais implicações da precarização do trabalho no tecido social, seja na 
organização sindical, nas relações de gênero, no desemprego ou na subjetividade do trabalhador. Mais do que elencar ementas de acórdãos que debatam o tema, objetiva-se observar a forma como determinados debates foram travados e a relação destes com as previsões positivadas em lei. Porque se a diretriz geral da precarização não parte do Judiciário, e sim de uma necessidade do capital, nos parece que é também a partir dos discursos e teses daquele que ela se coloca no cenário nacional. Justamente porque a retirada de direitos trabalhistas guarda semelhanças entre os diversos países inseridos na dinâmica capitalista, porém contém vicissitudes que caracterizam e distinguem os processos entre si, é que acreditamos que a doutrina e a jurisprudência podem ter relevo para entender essas particularidades. Ademais, relacionar as decisões jurisprudenciais com os textos legais relativos à jornada permite uma compreensão acerca de quais as teses que de fato embasaram o processo legislativo e qual a receptividade deles pelos Tribunais.

Para lograr a obtenção de respostas para as hipóteses aventadas, a metodologia analítica perpassará pela conexão entre o contexto político-econômico e as novas formas combinadas de organização da produção a fim de compreender o papel que a jornada de trabalho assume no processo de ampliação das taxas de lucratividade. Assim, inicia-se com uma análise calcada em revisão bibliográfica a fim de traçar o panorama macroeconômico e a relação destas com as medidas de alargamento da flexibilização do Direito do Trabalho, partindo do início do Século XX e culminando no impeachment da presidenta Dilma Rousseff e aprovação da Lei $\mathrm{n}^{\circ} 13.467 / 2017$.

No que diz respeito ao objeto empírico, a jurisprudência, nos limitaremos a analisar decisões sobre os contratos de trabalho regidos pela CLT, ou seja, excluiremos os debates envolvendo servidores públicos submetidos ao regime estatutário, tanto por serem aqueles o objeto de regulamentação do Direito do Trabalho como por serem o locus prioritário de aplicação das medidas de austeridade. Ainda, o foco será nas relações de emprego, posto que abordar as demais formas de relação de trabalho e adentrar no campo do trabalho informal não é esfera passível da análise jurisprudencial que realizaremos.

A flexibilização da jornada pode ser observada em diversos institutos e vem em inúmeros formatos. Para afunilar o objeto, foram eleitas algumas modalidades de flexibilização que tiveram alterações em sua regulamentação legal e que foram 
objeto de jurisprudência sumulada pelo TST ou STF, bem como que possuem maior presença nos contratos de trabalho, tendo em vista que algumas modalidades, como o contrato por tempo parcial, não foram utilizadas em larga escala. Assim, elegemos três formatos de jornada flexível como objeto para o estudo empírico: a compensação semanal, a compensação anual ("banco de horas") e a jornada em escalas de revezamento (que engloba a jornada 12x36 e os turnos ininterruptos de revezamento).

Analisaremos em um primeiro momento a aplicação da flexibilização a partir das Súmulas dos Tribunais Superiores e Orientações Jurisprudenciais, por vincularem a interpretação das demais instâncias e por expressarem a posição majoritária da Corte Trabalhista. Não pretendemos nos deter nas sentenças de primeiro grau e acórdãos dos Tribunais Regionais, posto que, além de serem incontáveis, consistem em decisões que muitas vezes destoam dos entendimentos dominantes. Alguns acórdãos do Tribunal Superior do Trabalho foram também utilizados com vistas a ilustrar posições ainda não trazidas em textos sumulares.

O foco na jurisprudência trabalhista não implica em excluir as decisões do Supremo Tribunal Federal. Embora em menor número, elas têm grande reverberação nos processos da justiça especializada, especialmente quando há reconhecimento de repercussão geral, ou seja, casos nos quais todos os processos pendentes de julgamento de recursos podem, a depender da pertinência temática, ficar sobrestados até a decisão proferida no processo principal pelo STF, a qual vinculará o entendimento nos demais. Não nos propomos a analisar os acórdãos do Supremo Tribunal de Justiça, pois trabalharemos somente com o setor privado e suas formas de flexibilização.

Quanto ao critério temporal, buscaremos analisar, em um primeiro momento, os julgados que serviram de precedente para as Súmulas e Orientações Jurisprudenciais do TST, bem como aqueles que expressavam entendimentos diversos no mesmo período. Tal análise intenta auferir a tônica dos debates que deram origem aos entendimentos sumulados e, a partir disso, verificar como a flexibilização era abordada pelos partidários da tese vencedora e das teses divergentes, além dos argumentos utilizados por ambos.

A leitura da jurisprudência não tem a perspectiva de uma análise quantitativa, e sim possibilitar a identificação de quais as tendências jurisprudenciais quanto ao tema da flexibilização da jornada e quais os 
posicionamentos adotados pelos Tribunais em relação aos seus mais variados aspectos. Até por entendermos que a pesquisa dificilmente concluirá que a jurisprudência assume um único papel nesse processo, a intenção é abordar a complexidade do tema, suas nuances e os argumentos utilizados para justificar as decisões. Em termos de recorte temporal, abordaremos todas as Súmulas e Orientações Jurisprudenciais do STF e TST que se relacionam com os institutos flexibilizadores eleitos.

A partir desses delineamentos é que buscamos proceder à análise da jurisprudência trabalhista relativa à flexibilização da jornada, na expectativa que ela elucide os problemas arrolados e contribua com os estudos sobre a interpretação conferida pelos Tribunais ao tema. 


\section{CONCLUSÃO}

A legislação trabalhista brasileira surgiu com maior relevância e adquiriu importância na medida em que serviu à instituição de um novo padrão de acumulação no país, voltado para a estrutura produtiva de base urbano-industrial, o que ocorreu em paralelo à manutenção dos privilégios das classes proprietárias rurais, cujos trabalhadores não foram contemplados pelas normas contidas na CLT, assim como os trabalhadores domésticos. No que tange à jornada, a CLT já previa, junto da limitação em 8 horas de trabalho diário, exceções à sua aplicação e a possibilidade de sua compensação de um dia para outro dentro do módulo semanal, o que denota um caráter pouco rígido da jornada desde a sua origem. Posteriormente, o golpe militar, na defesa dos interesses das classes dominantes, estruturou a produção de bens de consumo duráveis para parcela da população com maior poder aquisitivo ao mesmo tempo que desenvolveu um polo voltado para a exportação de produtos primários e produtos industrializados de consumo, processo desacompanhado da ampliação de garantias sociais e trabalhistas para a população. Nesse período, a criação do FGTS, em substituição à estabilidade decenal, e a edição da Lei $n^{\circ} 6.019 / 1974$, que criou a figura do trabalho temporário, foram inovações inseridas em uma primeira onda de flexibilização, já voltada para a maximização dos lucros em prol da destruição das garantias até então assentadas pela legislação.

Com a ascensão dos movimentos sociais no final dos anos 1970 e, posteriormente, o fim da ditadura militar, instituiu-se a Assembleia Nacional Constituinte e deu-se inícios às discussões para a formulação do que viria a ser a Constituição Federal de 1988. Fruto de um momento de acalorados embates políticos, as disposições relativas à jornada exprimem a ambivalência das normas constitucionais. Se por um lado os direitos relativos às relações de trabalho foram alçados ao patamar constitucional, incorporados aos demais direitos sociais, por outro as limitações à duração da jornada foram condicionadas à negociação coletiva, denotando uma abertura ao avanço do processo de flexibilização.

O avanço dos governos neoliberais na década de 1990 consolidou a ampliação das políticas de austeridade direcionadas para o aumento da regulação privada do trabalho, em detrimento da regulação pública. A desindexação salarial, 
a instituição da compensação de jornada anual e a autorização do trabalho aos domingos compuseram o bojo de medidas que atenderam as demandas do capitalismo financeirizado para os países periféricos, expressadas no Consenso de Washington ${ }^{\circ} \mathrm{Na}$ sequência, os governos petistas foram marcados pelo aumento da formalização dos postos de trabalho, principalmente com a criação de empregos de baixa remuneração. Embora tenha havido um arrefecimento na aplicação de medidas de cunho abertamente neoliberal, retrocessos para os trabalhadores foram identificados, como na aprovação da reforma da previdência em 2005, MPs 664 e 665 de 2014 e a Lei $n^{\circ} 13.103 / 2015$ (sobre o trabalho dos motoristas profissionais).

Com o golpe desferido ao governo da presidenta Dilma Rousseff, a agenda de precarização do trabalho voltou com toda a força, cuja expressão máxima é a aprovação em tempo recorde da Lei n¹3.467/2017, a 'reforma trabalhista'.

Essa incursão pela história das normas relativas à jornada possibilitou observar como a regulamentação da jornada no Brasil sempre comportou exceções à limitação e possibilidades de compensação. A flexibilização, conceito que denota maior maleabilidade e afrouxamento da proteção trabalhista clássica, ainda que potencializada com a ascensão do capitalismo flexível e necessidade de redução de gastos com o trabalho, sempre se fez presente no cenário nacional. Consiste no que José Dari Krein denominou de padrão flexível de regulação do trabalho, evidenciado pelo permanente alto grau de flexibilidade nas condições de seu uso e de remuneração. A limitação à jornada diária e semanal, desde a origem da CLT, já comportava exceções, que foram ampliadas com o passar dos anos por meio de alterações ao texto celetista e introdução de novas figuras.

O direito do trabalho, junto de tais normas, confere destacada importância à jurisprudência, sendo esta a responsável por inúmeras alterações e inovações no âmbito da matéria nas últimas décadas. Dentro desse cenário, foi traçado um problema inicial para nortear a presente pesquisa, consistente na análise de quais as posições assumidas pela jurisprudência quanto à flexibilização da jornada.

Após a leitura da jurisprudência sobre a jornada de trabalho consolidada pelo TST e STF sobre os institutos eleitos (compensação semanal, banco de horas, turnos ininterruptos de revezamento e jornada 12×36), foi possível traçar três conclusões sobre essa interação. 
A primeira é a de que ambas as Cortes recepcionaram os textos legais que instituíram os regimes estudados, sem indícios de questionamentos de sua constitucionalidade nos acórdãos por elas proferidos e recusa de sua aplicação nos casos concretos. A despeito de parcela importante da doutrina ter se posicionado pela inconstitucionalidade de normas como a Lei $n^{\circ} 9.601 / 1998$, que instituiu 0 banco de horas, tal posição não encontrou escopo nas decisões proferidas pelo STF e TST, demonstrando uma reticência dessas instâncias em confrontar diretamente as medidas instituídas pelos demais poderes, mesmo que frontalmente contrárias à jurisprudência até então dominante.

A segunda conclusão é que, se por um lado não houve um enfrentamento mais energético às leis instituídas, por outro a jurisprudência assimilou o entendimento que reconhece nos regimes compensatórios, em sua maioria, prejuízos à saúde e convívio familiar e social do trabalhador. As súmulas e OJs aprovadas, principalmente após o fim dos anos 1990, calcadas nessa argumentação, buscam obstaculizar a adoção desmesurada da jornada flexível, por meio da instituição de critérios rígidos para conferir validade ao regime e fórmulas mais benéficas ao empregado para cálculo das horas extraordinárias oriundas da sua nulidade. A ampliação do conceito de turnos ininterruptos de revezamento, com vistas a enquadrar a jornada desempenhada na limitação constitucional de 6 horas diárias, é um exemplo que destaca essa atuação.

A terceira conclusão, por sua vez, identifica uma maior permissividade à flexibilização da jornada no âmbito das negociações coletivas, com a jurisprudência majoritariamente validando as normas coletivas que preveem jornadas superiores à $8^{\underline{a}}$ diária e $44^{\underline{a}}$ semanal nos regimes de compensação. Exceções à parte, a tônica geral é a de reconhecimento da autonomia privada coletiva e livre negociação das partes em temas onde houve autorização para tal no texto constitucional.

Muito embora no país predomine um padrão de regulação do trabalho flexível, foi possível identificar que a jurisprudência não atua permanentemente sob essa lógica. Confirmou-se a hipótese traçada inicialmente de que a atuação majoritariamente se dá em uma perspectiva mais garantista ao trabalhador, ainda que, frisa-se novamente, com as já mencionadas limitações, mormente pelas decisões em consonância com a primazia da regulação privada buscada pelas classes dominantes. 
Se historicamente os Tribunais hesitaram em declarar a inconstitucionalidade e inaplicabilidade de normas cujas previsões eram entendidas até então como inconstitucionais, um desafio se coloca para os próximos anos, face às alterações trazidas pela Lei $n^{\circ}$ 13.467/2017. Parte significativa, para não dizer a maioria, das mudanças implementadas colide com entendimentos jurisprudenciais expressados pelo TST até então. O Tribunal irá confrontar essa ofensiva legal, entrando em combate com as demandas dos capitalistas, ou se curvará à sua recepção, revisando suas súmulas e restringindo sua intervenção à criação de obstáculos? Os cortes orçamentários e crescente ameaça de extinção do direito e da Justiça do Trabalho serão capazes de intimidar os julgadores? De nossa parte, esperamos que a compreensão da destruição causada pela precarização do trabalho motive-os a encampar a defesa à ofensiva perpetrada. 


\section{REFERÊNCIA BIBLIOGRÁFICA}

\section{Legislação}

BRASIL. Lei $n^{\circ} 4.330$, de $1^{\circ}$ de junho de 1964. Regula o direito de greve, na forma do art. 158, da Constituição Federal. Disponível em:

<http://www.planalto.gov.br/Ccivil_03/LEIS/1950-1969/L4330.htm>. Acesso em: 10 abril 2018.

BRASIL. Lei $n^{\circ}$ 4.886, de 9 de dezembro de 1965. Regula as atividades dos representantes comerciais autônomos. Disponível em:

<http://www.planalto.gov.br/ccivil_03/LEIS/L4886.htm>. Acesso em: 10 abril 2018.

BRASIL. Lei $n^{\circ}$ 4.923, de 23 de dezembro de 1965. Institui o Cadastro Permanente das Admissões e Dispensas de Empregados, Estabelece Medidas Contra o Desemprego e de Assistência aos Desempregados, e dá outras Providências. Disponível em:

<http://www.planalto.gov.br/ccivil_03/LEIS/L4923.htm>. Acesso em: 03 maio 2018.

BRASIL. Lei $n^{\circ} 5.107$, de 13 de setembro de 1966. Cria o Fundo de Garantia do Tempo de Serviço, e dá outras providências. Disponível em: < https://www.planalto.gov.br/ccivil_03/LEIS/L5107.htm>. Acesso em: 10 abril 2018.

BRASIL. Lei $n^{\circ} 5.811$, de 11 de outubro de 1972. Dispõe sobre o regime de trabalho dos empregados nas atividades de exploração, perfuração, produção e refinação de petróleo, industrialização do xisto, indústria petroquímica e transporte de petróleo e seus derivados por meio de dutos. Disponível em: < http://www.planalto.gov.br/ccivil_03/LEIS/1970-1979/L5811.htm>. Acesso em: 25 ago 2018.

BRASIL. Lei $n^{\circ} 6.494$, de 7 de dezembro de 1977. Dispõe sobre os estágios de estudantes de estabelecimento de ensino superior e ensino profissionalizante do $2^{\circ}$ Grau e Supletivo e dá outras providências. Disponível em: <http://www.planalto.gov.br/ccivil_03/LEIS/L6494.htm>. Acesso 10 abril 2018.

BRASIL. Lei $n^{\circ}$ 7.102, de 20 de junho de 1983. Dispõe sobre segurança para estabelecimentos financeiros, estabelece normas para constituição e funcionamento das empresas particulares que exploram serviços de vigilância e de transporte de valores, e dá outras providências. Disponível em: < http://www.planalto.gov.br/ccivil_03/LEIS/L7102.htm>. Acesso em: 10 abril 2018.

BRASIL. Lei $n^{\circ} 7.701$, de 21 de dezembro de 1988. Dispõe sobre a especialização de Turmas dos Tribunais do Trabalho em processos coletivos e dá outras providências. Disponível em: < http://www.planalto.gov.br/ccivil_03/LEIS/L7701.htm>. Acesso em: 12 ago 2018.

BRASIL. Lei $n^{\circ}$ 8.863, de 28 de março de 1994. Altera a Lei $n^{\circ}$ 7.102, de 20 de junho de 1983. Disponível em: <http://www2.camara.leg.br/legin/fed/lei/1994/lei- 
8863-28-marco-1994-349768-publicacaooriginal-1-pl.html>. Acesso em: 02 maio 2018.

BRASIL. Lei no 9.601, de 21 de janeiro de 1998. Dispõe sobre o contrato de trabalho por prazo determinado e dá outras providências. Disponível em <http://www.planalto.gov.br/ccivil_03/leis/L9601.htm>. Acesso em: 12 jun 2018.

BRASIL. Lei $n^{\circ}$ 9.756, de 17 de dezembro de 1998. Dispõe sobre o processamento de recursos no âmbito dos tribunais. Disponível em: < http://www.planalto.gov.br/ccivil_03/LEIS/L9756.htm>. Acesso em: 15 ago 2018.

BRASIL. Lei $n^{\circ} 10.101$, de 19 de dezembro de 2000. Dispõe sobre a participação dos trabalhadores nos lucros ou resultados da empresa e dá outras providências. Disponível em: <http://www.planalto.gov.br/ccivil_03/Leis/L10101.htm>. Acesso 12 jun 2018.

BRASIL. Lei $n^{\circ} 10.243$, de 19 de junho de 2001. Acrescenta parágrafos ao art. 58 e dá nova redação ao $\S 20$ do art. 458 da Consolidação das Leis do Trabalho, aprovada pelo Decreto-Lei no 5.452, de 10 de maio de 1943. Disponível em: <http://www.planalto.gov.br/ccivil_03/LEIS/LEIS_2001/L10243.htm>. Acesso 12 jun 2018.

BRASIL. Medida provisória $n^{\circ} 2.164-41$, de 24 de agosto de 2001. Altera a Consolidação das Leis do Trabalho - CLT, para dispor sobre o trabalho a tempo parcial, a suspensão do contrato de trabalho e o programa de qualificação profissional, modifica as Leis nos 4.923, de 23 de dezembro de 1965, 5.889, de 8 de junho de 1973, 6.321, de 14 de abril de 1976, 6.494, de 7 de dezembro de 1977, 7.998, de 11 de janeiro de 1990, 8.036, de 11 de maio de 1990, e 9.601, de 21 de janeiro de 1998, e dá outras providências. Disponível em:

<http://www2.camara.leg.br/legin/fed/medpro/2001/medidaprovisoria-2164-41-24agosto-2001-390727-normaatualizada-pe.html>. Acesso 12 jun 2018.

BRASIL. Lei $n^{\circ} 11.101$, de 9 de fevereiro de 2005. Regula a recuperação judicial, a extrajudicial e a falência do empresário e da sociedade empresária. Disponível em: <https://www.planalto.gov.br/ccivil_03/_Ato2004-2006/2005/Lei/L11101.htm>. Acesso em:10 jul 2018.

BRASIL. Emenda Constitucional $n^{\circ} 72$, de 2 de abril de 2013. Altera a redação do parágrafo único do art. $7^{\circ}$ da Constituição Federal para estabelecer a igualdade de direitos trabalhistas entre os trabalhadores domésticos e os demais trabalhadores urbanos e rurais. Disponível em: < http://www.planalto.gov.br/ccivil_03/Constituicao/Emendas/Emc/emc72.htm>. Acesso em:10 jul 2018.

BRASIL. Lei no 13.015, de 21 de julho de 2014. Altera a Consolidação das Leis do Trabalho (CLT), aprovada pelo Decreto-Lei no 5.452, de 10 de maio de 1943, para dispor sobre o processamento de recursos no âmbito da Justiça do Trabalho. Disponível em: < http://www.planalto.gov.br/CCIVIL_03/_Ato2011-

2014/2014/Lei/L13015.htm>. Acesso em: 12 ago 2018. 
BRASIL. Lei $n^{\circ} 13.103$, de 2 de março de 2015. Dispõe sobre o exercício da profissão de motorista; altera a Consolidação das Leis do Trabalho - CLT, aprovada pelo Decreto-Lei no 5.452, de 10 de maio de 1943, e as Leis nos 9.503, de 23 de setembro de 1997 - Código de Trânsito Brasileiro, e 11.442, de 5 de janeiro de 2007 (empresas e transportadores autônomos de carga), para disciplinar a jornada de trabalho e o tempo de direção do motorista profissional; altera a Lei no 7.408, de 25 de novembro de 1985; revoga dispositivos da Lei no 12.619, de 30 de abril de 2012; e dá outras providências. Disponível em: <http://www.planalto.gov.br/ccivil_03/_Ato2015-2018/2015/Lei/L13103.htm>. Acesso em:14 jun 2018.

BRASIL. Lei no 13.439, de 31 de março de 2017. Altera dispositivos da Lei no 6.019 , de 3 de janeiro de 1974, que dispõe sobre o trabalho temporário nas empresas urbanas e dá outras providências; e dispõe sobre as relações de trabalho na empresa de prestação de serviços a terceiros. Disponível em: < http://www.planalto.gov.br/ccivil_03/_ato2015-2018/2017/lei/L13429.htm>. Acesso em: 18 out 2018.

BRASIL. Lei no 13.467, e 13 de julho de 2017. Altera a Consolidação das Leis do Trabalho (CLT), aprovada pelo Decreto-Lei no 5.452, de 10 de maio de 1943, e as Leis nos 6.019, de 3 de janeiro de 1974, 8.036, de 11 de maio de 1990, e 8.212, de 24 de julho de 1991, a fim de adequar a legislação às novas relações de trabalho. Disponível em: < http://www.planalto.gov.br/ccivil_03/_Ato20152018/2017/Lei/L13467.htm>. Acesso em: 12 out 2018.

\section{Súmulas, OJs e Regimentos do TST}

RE 49296-São Paulo. Relator: Ministro Antônio Martins Vilas Bôas. Data de julgamento: 09/01/1962. 2ª Turma. Publicação: DJ de 02/04/1962. Disponível em: $<$ http://redir.stf.jus.br/paginadorpub/paginador.jsp?docTP=AC\&doclD=148394>. Acesso em: 25 ago 2018.

BRASIL. Supremo Tribunal Federal. Súmula $n^{\circ}{ }^{213}$. É devido o adicional de serviço noturno, ainda que sujeito o empregado ao regime de revezamento. Data de Aprovação: Sessão Plenária de 13/12/1963. Súmula da Jurisprudência Predominante do Supremo Tribunal Federal - Anexo ao Regimento Interno. Edição: Imprensa Nacional, 1964, p. 104.

BRASIL. Supremo Tribunal Federal. Súmula $n^{\circ} 214$. A duração legal da hora de serviço noturno (52 minutos e trinta segundos) constitui vantagem suplementar que não dispensa o salário adicional. Data de Aprovação: Sessão Plenária de 13/12/1963. Súmula da Jurisprudência Predominante do Supremo Tribunal Federal - Anexo ao Regimento Interno. Edição: Imprensa Nacional, 1964, p. 105.

BRASIL. Tribunal Superior do Trabalho. Súmula $n^{\circ} 85$. Compensação de jornada. Brasília, DF: Tribunal Superior do Trabalho, DJ 26.09.1978. Disponível em: $<$ http://www3.tst.jus.br/jurisprudencia/Sumulas_com_indice/Sumulas_Ind_51_100. html\#SUM-85>. Acesso em: 08 ago 2018. 
BRASIL. Tribunal Superior do Trabalho. Súmula $n^{\circ} 108$. Brasília, DF: Tribunal Superior do Trabalho, RA 75/1980, DJ 21.07.1980. Disponível em:

<http://www3.tst.jus.br/jurisprudencia/Sumulas_com_indice/Sumulas_Ind_101_15 0.html\#SUM-108>. Acesso em: 08 ago 2018.

BRASIL. Tribunal Superior do Trabalho. Súmula no 130. Brasília, DF: Tribunal Superior do Trabalho, RA 102/1982, DJ 11.10.1982 e DJ 15.10.1982. Disponível em:

<http://www3.tst.jus.br/jurisprudencia/Sumulas_com_indice/Sumulas_Ind_101_15 0.html\#SUM-130>. Acesso em: 25 ago 2018.

BRASIL. Tribunal Superior do Trabalho. Súmula $n^{\circ} 256$. Contrato de prestação de serviços. Legalidade (cancelada). Brasília, DF: Tribunal Superior do Trabalho, Res. 4/1986, DJ 30.09.1986, 01 e 02.10.1986. Disponível em: < http://www3.tst.jus.br/jurisprudencia/Sumulas_com_indice/Sumulas_Ind_251_300. html\#SUM-256>. Acesso em: 10 de maio de 2018.

BRASIL. Tribunal Superior do Trabalho. Súmula $n^{\circ} 331$. Contrato de prestação de serviços. Legalidade. Brasília, DF: Tribunal Superior do Trabalho, Res. 23/1993, DJ 21, 28.12.1993 e 04.01.1994. Disponível em: < http://www3.tst.jus.br/jurisprudencia/Sumulas_com_indice/Sumulas_Ind_301_350. html\#SUM-331>. Acesso em: 10 de maio de 2018.

BRASIL. Tribunal Superior do Trabalho. Súmula $n^{\circ} 360$. Turnos ininterruptos de revezamento. Intervalos intrajornada e semanal. Brasília, DF: Tribunal Superior do Trabalho, Res. 79/1997, DJ 13, 14 e 15.01.1998. Disponível em: $<$ http://www3.tst.jus.br/jurisprudencia/Sumulas_com_indice/Sumulas_Ind_351_40 0.html\#SUM-360>. Acesso em: 28 ago 2018.

BRASIL. Tribunal Superior do Trabalho (Subseção I Especializada em Dissídios Individuais - SBDI I). OJ $n^{\circ} 169$. Turno ininterrupto de revezamento. Fixação de jornada de trabalho mediante negociação coletiva. Validade. Brasília, DF: Tribunal Superior do Trabalho [1999]. Disponível em:

<http://www3.tst.jus.br/jurisprudencia/OJ_SDI_1/n_s1_161.htm\#TEMA169>. Acesso em: 28 ago 2018.

BRASIL. Tribunal Superior do Trabalho. (Subseção I Especializada em Dissídios Individuais - SBDI I). OJ $n^{\circ} 275$. Turno ininterrupto de revezamento. Horista. Horas extras e adicional. Devidos. Brasília, DF: Tribunal Superior do Trabalho [2002]. Disponível em: <http://www3.tst.jus.br/jurisprudencia/OJ_SDI_1/n_s1_261.htm\#TEMA275>. Acesso em: 28 ago 2018.

BRASIL. Supremo Tribunal Federal. Súmula $n^{\circ} 675$. Os intervalos fixados para descanso e alimentação durante a jornada de seis horas não descaracterizam o sistema de turnos ininterruptos de revezamento para o efeito do art. $7^{\circ}, \mathrm{XIV}$, da Constituição. Data de Aprovação: Sessão Plenária de 24/09/2003. DJ de 09/10/2003, p. 4; DJ de 10/10/2003, p. 4; DJ de 13/10/2003, p. 4. 
BRASIL. Tribunal Superior do Trabalho. Súmula n. 85. Compensação de horário. Brasília, DF: Tribunal Superior do Trabalho, Res. 121/2003, DJ 19, 20 e 21.11.2003. Disponível em:

<http://www3.tst.jus.br/jurisprudencia/Sumulas_com_indice/Sumulas_Ind_51_100. html\#SUM-85>. Acesso em: 08 ago 2018.

BRASIL. Tribunal Superior do Trabalho (Subseção I Especializada em Dissídios Individuais - SBDI I). OJ $n^{\circ} 342$. Intervalo intrajornada para repouso e alimentação. Não concessão ou redução. Previsão em norma coletiva. Validade. Brasília, DF: Tribunal Superior do Trabalho, DJ 22.06.2004. Disponível em: <http://www3.tst.jus.br/jurisprudencia/OJ_SDI_1/n_s1_341.htm\#TEMA342>. Acesso em: 23 ago 2018.

BRASIL. Tribunal Superior do Trabalho (Subseção I Especializada em Dissídios Individuais - SBDI I). OJ $n^{\circ} 182$. Compensação de jornada. Acordo individual. Validade (cancelada em decorrência da nova redação conferida à Súmula no 85). Brasília, DF: Tribunal Superior do Trabalho, Res. 129/2005, DJ 20, 22 e 25.04.2005. Disponível em:

<http://www3.tst.jus.br/jurisprudencia/OJ_SDI_1/n_s1_181.htm\#TEMA182>. Acesso em: 08 ago 2018.

BRASIL. Tribunal Superior do Trabalho (Subseção I Especializada em Dissídios Individuais - SBDI I). OJ $n^{\circ} 220$. Acordo de compensação. Extrapolação da jornada. (cancelada em decorrência da nova redação conferida à Súmula no 85 ). Brasília, DF: Tribunal Superior do Trabalho, Res. 129/2005, DJ 20, 22 e 25.04.2005. Disponível em:

<http://www3.tst.jus.br/jurisprudencia/OJ_SDI_1/n_s1_201.htm\#TEMA220>. Acesso em: 08 ago 2018.

BRASIL. Tribunal Superior do Trabalho (Subseção I Especializada em Dissídios Individuais - SBDI I). OJ $n^{\circ} 223$. Compensação de jornada. Acordo individual tácito. Inválido. (cancelada em decorrência da nova redação conferida à Súmula no 85). Brasília, DF: Tribunal Superior do Trabalho, Res. 129/2005, DJ 20, 22 e 25.04.2005. Disponível em:

<http://www3.tst.jus.br/jurisprudencia/OJ_SDI_1/n_s1_221.htm\#TEMA223>. Acesso em: 08 ago 2018.

BRASIL. Tribunal Superior do Trabalho. Súmula n. 85. Compensação de jornada (incorporadas as Orientações Jurisprudenciais nํㅗ 182, 220 e 223 da SBDI-1).

Brasília, DF: Tribunal Superior do Trabalho, Res. 129/2005, DJ 20, 22 e 25.04.2005. Disponível em:

$<$ http://www3.tst.jus.br/jurisprudencia/Sumulas_com_indice/Sumulas_Ind_51_100. html\#SUM-85>. Acesso em: 10 ago 2018.

BRASIL. Tribunal Superior do Trabalho. Súmula $n^{\circ}$ 423. Turno ininterrupto de revezamento. Fixação de jornada de trabalho mediante negociação coletiva.

Validade. Brasília, DF: Tribunal Superior do Trabalho, Res. 139/2006 - DJ 10, 11 e 13.10.2006. Disponível em: <

http://www3.tst.jus.br/jurisprudencia/Sumulas_com_indice/Sumulas_Ind_401_450. html\#SUM-423>. Acesso em: 28 ago 2018. 
BRASIL. Tribunal Superior do Trabalho (Subseção I Especializada em Dissídios Individuais - SBDI I). $\mathrm{OJ} n^{\circ} 360$. Turno ininterrupto de revezamento. Dois turnos. Horário diurno e noturno. Caracterização. ). Brasília, DF: Tribunal Superior do Trabalho, DJ 14.03.2008. Disponível em:

<http://www3.tst.jus.br/jurisprudencia/OJ_SDI_1/n_s1_341.htm\#TEMA360>. Acesso em: 38 ago 2018.

BRASIL. Tribunal Superior do Trabalho (Subseção I Especializada em Dissídios Individuais - SBDI I). OJ $n^{\circ} 388$. Jornada $12 \times 36$. Jornada mista que compreenda a totalidade do período noturno. Adicional noturno. Devido. Brasília, DF: Tribunal Superior do Trabalho, DEJT divulgado em 09, 10 e 11.06.2010. Disponível em: <http://www3.tst.jus.br/jurisprudencia/OJ_SDI_1/n_s1_381.html\#TEMA388>. Acesso em: 20 ago 2018.

BRASIL. Tribunal Superior do Trabalho (Subseção I Especializada em Dissídios Individuais - SBDI I). $O J n^{\circ} 395$. Turno ininterrupto de revezamento. Hora noturna reduzida. Incidência. Brasília, DF: Tribunal Superior do Trabalho, DEJT divulgado em 09, 10 e 11.06.2010. Disponível em:

<http://www3.tst.jus.br/jurisprudencia/OJ_SDI_1/n_s1_381.html\#TEMA395>. Acesso em: 28 ago 2018

BRASIL. Tribunal Superior do Trabalho (Subseção I Especializada em Dissídios Individuais - SBDI I). OJ $n^{\circ} 396$. Turnos ininterruptos de revezamento. Alteração da jornada de oito para seis horas diárias. Empregado horista. Aplicação do divisor 180. Brasília, DF: Tribunal Superior do Trabalho, DEJT divulgado em 09, 10 e 11.06.2010. Disponível em:

<http://www3.tst.jus.br/jurisprudencia/OJ_SDI_1/n_s1_381.html\#TEMA396>. Acesso em: 28 ago 2018.

BRASIL. Tribunal Superior do Trabalho. Súmula n. 85. Compensação de jornada Res. 174/2011, DEJT divulgado em 27, 30 e 31.05.2011. Brasília, DF: Tribunal Superior do Trabalho, Res. 174/2011, DEJT divulgado em 27, 30 e 31.05.2011. Disponível em: <

http://www3.tst.jus.br/jurisprudencia/Sumulas_com_indice/Sumulas_Ind_51_100.h tml\#SUM-85>. Acesso em: 17 ago 2018.

BRASIL. Tribunal Superior do Trabalho. Súmula n. 349. Acordo de compensação de horário em atividade insalubre, celebrado por acordo coletivo. Validade. (cancelada). Brasília, DF: Tribunal Superior do Trabalho, Res. 174/2011, DEJT divulgado em 27, 30 e 31.05.2011. Disponível em: <

http://www3.tst.jus.br/jurisprudencia/Sumulas_com_indice/Sumulas_Ind_301_350. html\#SUM-349>. Acesso em: 10 ago 2018.

BRASIL. Tribunal Superior do Trabalho (Subseção I Especializada em Dissídios Individuais - SBDI I). OJ $n^{\circ} 420$. Turnos ininterruptos de revezamento. Elastecimento da jornada de trabalho. Norma coletiva com eficácia retroativa. Invalidade. Brasília, DF: Tribunal Superior do Trabalho, DEJT divulgado em 28 e 29.06.2012 e 02.07.2012. Disponível em: < 
http://www3.tst.jus.br/jurisprudencia/OJ_SDI_1/n_s1_401.html\#TEMA420>. Acesso em: 28 ago 2018.

BRASIL. Tribunal Superior do Trabalho. Súmula $n^{\circ}$ 437. Intervalo intrajornada para repouso e alimentação. Aplicação do art. 71 da CLT (conversão das Orientações Jurisprudenciais nำs 307, 342, 354, 380 e 381 da SBDI-1). Brasília, DF: Tribunal Superior do Trabalho, Res. 185/2012, DEJT divulgado em 25, 26 e 27.09.2012. Disponível em: < http://www3.tst.jus.br/jurisprudencia/Sumulas_com_indice/Sumulas_Ind_401_450. html\#SUM-437>. Acesso em: 23 ago 2018.

BRASIL. Tribunal Superior do Trabalho. Súmula $n^{\circ} 444$. Jornada de trabalho. Norma coletiva. Lei. Escala de 12 por 36. Validade. Brasília, DF: Tribunal Superior do Trabalho, Res. 185/2012, DEJT divulgado em 25, 26 e 27.09.2012 republicada em decorrência do despacho proferido no processo TST-PA504.280/2012.2 - DEJT divulgado em 26.11.2012. Disponível em:

<http://www3.tst.jus.br/jurisprudencia/Sumulas_com_indice/Sumulas_Ind_401_45 0.html\#SUM-444>. Acesso em: 20 ago 2018.

BRASIL. Tribunal Superior do Trabalho. Súmula n. 85. Compensação de jornada (inserido o item VI). Brasília, DF: Tribunal Superior do Trabalho, Res. 209/2016, DEJT divulgado em 01, 02 e 03.06.2016. Disponível em:

<http://www3.tst.jus.br/jurisprudencia/Sumulas_com_indice/Sumulas_Ind_51_100. html\#SUM-85>. Acesso em: 10 ago 2018.

BRASIL. Tribunal Superior do Trabalho. Regimento Interno do Tribunal Superior do Trabalho: aprovado pela Resolução Administrativa ํㅜ 1295/2008, com alterações dos Atos Regimentais nㅇs 1/2011, 2/2011, 3/2012, 4/2012, 5/2014, 6/2014, 7/2016 e 8/2016 e Emendas Regimentais nos 1/2011, 2/2011, 3/2012, 4/2012, 5/2014, 6/2016 e 7/2016. Brasília, TST, 2016. Disponível em: < https://juslaboris.tst.jus.br/bitstream/handle/20.500.12178/116169/2017_ra1937_ri tst_rep01.pdf?sequence=10\&isAllowed=y>. Acesso em: 12 ago 2018.

BRASIL. Tribunal Superior do Trabalho. Regimento Interno do Tribunal Superior do Trabalho: aprovado pela Resolução Administrativa $n^{\circ} 1.937$, de 20 de novembro de 2017. Brasília, TST, 2017. Disponível em:

<https://juslaboris.tst.jus.br/bitstream/handle/20.500.12178/116169/2017_ra1937_ ri_tst_rep01.pdf?sequence=10\&isAllowed=y>. Acesso em: 12 ago 2018.

\section{Demais publicações}

ALVES, Giovanni. Trabalho e mundialização do capital: a nova degradação do trabalho na era da globalização. Londrina: Práxis, 1999.

. Dimensões da reestruturação produtiva: ensaios de sociologia do trabalho. 2ª edição. Londrina: Práxis; Bauru: Canal 6, 2007.

ANTUNES, Ricardo A desertificação neoliberal no Brasil: Collor, FHC e Lula. Campinas: Autores Associados, 2005 
. Adeus ao Trabalho? Ensaios sobre as metamorfoses e a centralidade do mundo do trabalho. 16ª edição reimp, rev. e ampl. São Paulo: Cortez, 2015.

. O continente do labor. São Paulo: Boitempo Editorial, 2015.

. Os Sentidos do Trabalho: ensaios sobre a afirmação e a negação do trabalho. 2 ed. 10 reimp, rev. e ampl. São Paulo: Boitempo Editorial, 2009.

. Riqueza e miséria do trabalho no Brasil. São Paulo: Boitempo Editorial, 2006.

BARBOSA, Alexandre de Freitas. A formação do mercado de trabalho no Brasil. São Paulo: Alameda, 2008.

BIAVASCHI, Magda Barros; DROPPA, Alisson ${ }^{\circ}$ A história da Súmula 331 no Tribunal Superior do Trabalho: a alteração na forma de compreender a terceirização. Revista Mediações (UEL), v. 16, 2011.

BOITO JR., Armando. Política neoliberal e sindicalismo no Brasil. São Paulo: Xamã, 1999.

BRAGA, RUY. A vingança de Braverman: o infotaylorismo como contratempo. Em: ANTUNES, Ricardo; BRAGA, Ruy (orgs.). Infoproletários: degradação real do trabalho virtual. São Paulo: Boitempo, 2009, p. 59-88.

- A política do precariado: do populismo à hegemonia lulista. São Paulo: Boitempo Editorial, 2012.

; ANTUNES, Ricardo. Infoproletários: degradação real do trabalho virtual. São Paulo: Boitempo Editorial, 2009.

. Terra em transe: o fim do lulismo e o retorno da luta de classes. Em: SINGER, André; LOUREIRO, Isabel (orgs.). As contradições do lulismo: a que ponto chegamos?. São Paulo: Boitempo Editorial, 2016, p. 55-92.

BURAWOY, Michael. A transformação dos regimes fabris no capitalismo avançado. Revista Brasileira de Ciências Sociais. São Paulo: Anpocs, 1990, vol. 5, no 13, p. 29-50.

CARDOSO, Adalberto Moreira. Os sindicatos e o desemprego no Brasil. XXII Encontro Anual da ANPOCS, Caxambu. XXII Encontro Anual da ANPOCS. Resumos e Programação. São Paulo: ANPOCS, 1998, disponível em http://biblioteca.clacso.edu.ar/ar/libros/anpocs/badaro.rtf. Acesso em:10 set. 2017.

CARDOSO, Ana Cláudia Moreira. Tempos de trabalho, tempos de não trabalho: vivências cotidianas de trabalhadores. Tese (Doutorado) - Faculdade de Filosofia, Letras e Ciências Humanas, USP. São Paulo, 2007. 
. Direito e dever à desconexão: disputas pelos tempos de trabalho e não trabalho. Revista da Universidade Federal de Minas Gerais, v. 23, n 1 e 2, 2016.

CESARINO JÚNIOR, Antônio Ferreira. Direito social brasileiro. São Paulo: Martins, 1940.

CESIT. O debate sobre a reforma trabalhista e as MPE no Brasil. Campinas, UNICAMP/IE/CESIT, 2005. (Texto para Discussão n 18). Disponível em http://www.cesit.net.br/ cesit/images/stories/TextoParaDiscusso18.pdf. Acesso 23 abril 2018.

CHESNAIS, François. A Mundialização do Capital. Tradução Silvana Finzi Foá, São Paulo: Xamã. 1996.

CHIARELLI, Carlos Alberto Gomes. Trabalho na Constituição. São Paulo: LTr, 1989.

COUTINHO, Grijalbo Fernandes. O direito do trabalho flexibilizado por FHC e Lula. São Paulo: LTr, 2009. 2015. . Terceirização: máquina de moer gente trabalhadora. São Paulo: LTr,

DAL ROSSO, Sadi. O debate sobre a redução da jornada de trabalho. São Paulo: ABET, 1998.

. Mais trabalho! A intensificação do labor na sociedade contemporânea. São Paulo: Boitempo, 2008.

. Jornadas excessivas de trabalho. Em: Revista paranaense de desenvolvimento. Curitiba, v.34, ${ }^{\circ}{ }^{\circ 124, ~ p .73-91, ~ j a n ~ \% j u n ~}{ }^{2013}$. Disponível em: <http://www.ipardes.pr.gov.br/ojs/index.php/revista paranaense/article/view/581>. Acesso em:10 maio 2018.

. $O$ ardil da flexibilidade: os trabalhadores e a teoria do valor. São Paulo: Boitempo, 2017.

DELGADO, Maurício Godinho. Curso de Direito do Trabalho,11ª ed. São Paulo: LTr, 2012. 1998. . Jornada de trabalho e descansos trabalhistas, $2^{2}$ ed. São Paulo: LTr,

DIEESE. A Jornada de Trabalho nas Negociações Coletivas 1996 a 2004. Ano II № 16 - Dezembro de 2005. Disponível em:

$<$ https://www.dieese.org.br/estudosepesquisas/2005/estpesq16jornada200512.pdf >. Acesso em:01 nov. 2017. 
Relatório técnico: a jornada de trabalho no Brasil. Disponível em https://www.dieese.org.br/relatoriotecnico/2006/jornadaBrasil.pdf. Acesso 10 out. 2017.

Política de valorização do salário mínimo: valor para 2014 será de $\mathrm{R} \$$ 724,00. Nota Técnica, no 132, dezembro de 2013. São Paulo, DIEESE, 2013. Disponível em: <http://www.dieese.org.br/notatecnica/2013/notaTec132Salario Minimo2014.pdf>. Acesso em: 08 ago 2018.

FAUSTO, Bóris. Trabalho urbano e conflito social: 1890-1920. 2ª Ed. São Paulo: Companhia das Letras, 2016.

FELICIANO, Guilherme Guimarães. Curso crítico de direito do trabalho: teoria geral do direito do trabalho. São Paulo: Saraiva, 2013.

FERNANDES, Florestan ${ }^{\circ} \mathrm{A}$ revolução burguesa no Brasil. Rio de Janeiro: Jorge Zahar, 1975.

FONTES, Virgínia. Capitalismo em tempos de uberização: do emprego ao trabalho. Marx e o Marxismo - Revista do NIEP-Marx, [S.I.], v. 5, n 8, p. p. 45-67, jul. 2017. ISSN 2318-9657. Disponível em:

<http://www.niepmarx.blog.br/revistadoniep/index.php/MM/article/view/220.> Acesso em: 28 maio 2018.

- O Brasil e o capital-imperialismo: teoria e história. Rio de Janeiro: EPSJV/UFRJ, 2010.

GALVÃO, Andréia. Neoliberalismo e reforma trabalhista no Brasil. Rio de Janeiro: Revan; Fapesp, 2007.

et al. Dossiê reforma trabalhista. Campinas, Cesit/ie/Unicamp, 2017. Disponível em: <http://www.cesit.net.br/dossie-reforma-trabalhista>. Acesso em:18 out 2018.

GONSÁLEZ, Roberto Henrique S. Rotatividade: o fenômeno e seu contexto. Em: KREIN, José Dari [et. al] (orgs.). Regulação do trabalho e instituições públicas. São Paulo: Editora Perseu Abramo, 2013, pp. 229-246.

GUIMARÃES, José Ribeiro Soares. Perfil do Trabalho Decente no Brasil: um olhar sobre as Unidades da Federacão durante a segunda metade da década de 2000. Brasília: OIT, 2012, p. 118.

GUIMARÃES, Nadya Araújo; HIRATA, Helena (orgs). Trabalho flexível, empregos precários?: Uma comparação Brasil, França, Japão. São Paulo: Ed. USP, 2009.

HARVEY, David. O neoliberalismo: história e implicações. Tradução Adail Ubirajara Sobral e Maria Stela Gonçalves. São Paulo: Edições Loyola, 2008.

. O novo imperialismo. São Paulo: Edições Loyola, 2003. 
Condição pós-moderna. Tradução Adail Ubirajara Sobral. São Paulo:

Edições Loyola, 1994.

IBGE. Atlas do Censo Demográfico 2010. Rio de Janeiro: IBGE, 2013. Disponível em: <https://biblioteca.ibge.gov.br/index.php/biblioteca-

catalogo ?view=detalhes\&id=264529 . Acesso em: 20 maio 2018.

Síntese de indicadores sociais: uma análise das condições de vida da população brasileira. Rio de Janeiro: IBGE, 2017. Disponível em:

<https://biblioteca.ibge.gov.br/visualizacao/livros/liv101459.pdf>. Acesso em: 20 maio 2018.

KREIN, José Dari. Tendências recentes nas relações de emprego no Brasil: 19902005. Tese (Doutorado em Economia) - Universidade Estadual de Campinas, Instituto de Economia. Campinas: 2007.

As transformações no mundo do trabalho e as tendências das relações de trabalho na primeira década do século XXI no Brasil. Revista NECAT-Revista do Núcleo de Estudos de Economia Catarinense, v. 2, n 3, p. 6-25, 2014.

et al. Flexibilização das relações de trabalho: insegurança para os trabalhadores. Em: KREIN, D.; GIMENEZ, Denis Maracci; SANTOS, Anselmo Luis dos [ORGS]. Dimensões críticas da reforma trabalhista no Brasil. Campinas: Curt Nimuendajú, 2018.

- O desmonte dos direitos, as novas configurações do trabalho e o esvaziamento da ação coletiva: consequências da reforma trabalhista. Em: Tempo Social, revista de sociologia da USP, $2018, v .30, n^{\circ} 1$.

LEE, Sangheon; MCCANN, Deirdre; MESSENGER, Jon C. Duração do Trabalho em Todo o Mundo: Tendências de jornadas de trabalho, legislação e politicas numa perspectiva global comparada. Secretaria Internacional de Trabalho. Brasília: OIT, 2009

LESSA, Sergio. Trabalho e proletariado no capitalismo contemporâneo. São Paulo: Cortez, 2011.

LTR. Revista LTr. Suplemento Trabalhista $n^{\circ}$ 44/179, ano XV. São Paulo: LTr, 1979.

MACIEL, David. De Sarney a Collor reformas políticas, democratização e crise (1985-1990). 2008. Tese (Doutorado em História) - Faculdade de Ciências Humanas e Filosofia, UFG, Goiás.

MARCELINO, Paula. Trabalhadores terceirizados e a luta sindical. Curitiba: Editora Appris, 2013.

MARINGONI, Gilberto. Dez anos adiante. In: MEDEIROS, Juliano; DUTRA, Israel (orgs.). Um partido necessário: 10 anos do PSOL. Rio de Janeiro: Fundação Lauro Campos, 2016. 
MARTINS FILHO, Ives Gandra da Silva. Eixos de Transformação do Direito e do Processo do Trabalho. Em: MARTINS FILHO, Ives Gandra da Silva (org.) [et. al.]. Direito e processo do trabalho em transformação. Rio de Janeiro: Elsevier, 2007.

MARX, Karl. O capital: crítica da economia política. Livro I: O processo de produção do capital. Trad. Rubens Enderle. São Paulo: Boitempo, 2013.

MELLO E SILVA, Leonardo de. Trabalho e regresso: entre desregulamentação e re-regulação. Em: BRAGA, Ruy; RIZEK, Cibele Saliba. Hegemonia às avessas: economia, política e cultura na era da servidão financeira. Boitempo Editorial, 2010, pp. 61-92.

MIGUEL, Luis Felipe. A democracia na encruzilhada. Em: JINKINGS, Ivana; DORIA, Kim; CLETO, Murilo. Por que gritamos golpe? Para entender o impeachment e a crise política no Brasil. São Paulo: Boitempo, 2016.

NEVES, Magda de Almeida. Reestruturação produtiva, qualificação e relações de gênero. Em: ROCHA, Maria Isabel Baltar da (org.). Trabalho e gênero: mudanças, permanências e desafios. São Paulo: Editora 34, 2000, pp. 171-186.

NETO, José Salem. Repertório Jurisprudencial Trabalhista. São Paulo: Sugestões Literárias S/A, 1974.

OHNO, T., 1987, The Toyota production system. Cambridge: Productivity Press.

OLIVEIRA, Francisco de. Crítica à razão dualista/O ornitorrinco. São Paulo: Boitempo Editorial, 2015.

. Hegemonia às avessas: Em: DE OLIVEIRA, Francisco; BRAGA, Ruy; RIZEK, Cibele Saliba. Hegemonia às avessas: economia, política e cultura na era da servidão financeira. Boitempo Editorial, 2010.

; BRAGA, Ruy; RIZEK, Cibele Saliba. Hegemonia às avessas: economia, política e cultura na era da servidão financeira. Boitempo Editorial, 2010.

OLIVEIRA, Marco Antonio de. Política trabalhista e relações de trabalho no Brasil: da era Vargas ao governo FHC. Instituto de Economia da Universidade de Campinas (Tese de Doutorado), 2002.

OIT. Perfil do trabalho decente no Brasil. Brasília. Genebra: Escritório da Organização Internacional do Trabalho, 2009.

PAULANI, Leda Maria. A crise do regime de acumulação com dominância da valorização financeira e a situação do Brasil. Estudos avançados. São Paulo, v. 23, n66, p. 25-39, 2009. Disponível em http://producao.usp.br/handle/BDPI/6351. Acesso em:2 jul. 2017.

; ALMEIDA FILHO, Niemeyer. Regulação social e acumulação por espoliação - reflexão sobre a essencialidade das teses da financeirização e da 
natureza do Estado na caracterização do capitalismo contemporâneo. Campinas: Economia e sociedade, v. 20, p. 2, p. 243-272, ago. 2011. Disponível em: <http://www.scielo.br/pdf/ecos/v20n2/a02v20n2.pdf>. Acesso em: 01 nov. 2017.

PMDB. Uma ponte para o futuro. 29 de outubro de 2015. Disponível em https://www.fundacaoulysses.org.br/wp-content/uploads/2016/11/UMA-PONTEPARA-O-FUTURO.pdf. Acesso 12 out 2018.

POCHMANN, Márcio. Brasil sem industrialização: a herança renunciada. Ponta Grossa: Editora UEPG, 2016.

- Nova classe média? O trabalho na base de pirâmide social brasileira. Boitempo Editorial, 2012.

; BORGES, Altamiro. "Era FHC": a regressão do trabalho. São Paulo: Anita Garibaldi, 2002.

. Terceirização, competitividade e uberização do trabalho no Brasil. Em: TEIXEIRA, Marilane; ANDRADE, Hélio Rodrigues de; COELHO, Elaine D’Ávila (orgs.). Precarização e terceirização: faces da mesma realidade. São Paulo: Sindicato dos Químicos SP, 2016.

RAMOS FILHO, Wilson ${ }^{\circ} O$ direito capitalista do trabalho: história, mitos e perspectivas no Brasil. São Paulo: LTr, 2012

SANTOS, Anselmo Luis dos Santos; GIMENEZ, Denis Maracci. Desenvolvimento, competitividade e a reforma trabalhista. Em: KREIN, D.; GIMENEZ, Denis Maracci; SANTOS, Anselmo Luis dos [ORGS]. Dimensões críticas da reforma trabalhista no Brasil. Campinas: Curt Nimuendajú, 2018.

SANTOS, Wanderley Guilherme dos. Cidadania e justiça: a política social na ordem brasileira. São Paulo: Campus, 1979.

SEVERO, Valdete Souto. A interpretação constitucional e o banco de horas. Em: MELO FILHO, Hugo Cavalcanti [et. al.][orgs.]. O mundo do trabalho, volume l: leituras críticas da jurisprudência do TST: em defesa do direito do trabalho. São Paulo: LTr, 2009, p.439-470.

. Crise de paradigma no direito do trabalho moderno: a jornada. Porto Alegre: Sérgio Antonio Fabris, 2009.

. A interpretação constitucional e o banco de horas. Em: MELO FILHO, Hugo Cavalcanti [et. al.]. O mundo do trabalho, volume l: leituras críticas da jurisprudência do TST: em defesa do direito do trabalho. São Paulo: LTr, 2009.

SILVA. Homero Batista Mateus da. Curso de direito do trabalho aplicado, vol. 8: Justiça do Trabalho. Rio de Janeiro : Elsevier, 2010.

Curso de direito do trabalho aplicado, vol. 2: jornadas e pausas. Rio de Janeiro: Elsevier, 2013. 
SILVA, Josué Pereira da. Três discursos, uma sentença: tempo e trabalho em São Paulo, 1906/1932. São Paulo: ANNABLUME, 1996.

SILVA, Sayonara Grillo Coutinho Leonardo da. Direitos fundamentais, garantismo e direito do trabalho. Direitos fundamentais, garantismo e direito do trabalho. Em: Revista do TST, Brasília, vol. 77, no 3, jul/set, 2011, p. 286.

SINGER, André. Os sentidos do Iulismo. São Paulo: Companhia das Letras, 2012. ; LOUREIRO, Isabel (orgs.). As contradições do lulismo: a que ponto chegamos?. São Paulo: Boitempo Editorial, 2016.

SOUTO MAIOR, Jorge Luiz. O direito do trabalho como instrumento de justiça social. São Paulo: LTr, 2000

. História do Direito do Trabalho no Brasil. Curso de Direito do Trabalho, vol. I, parte II. São Paulo: LTr, 2017.

URIARTE, Oscar Ermida. A flexibilidade. Trad. Edilson Alkmin Cunha. São Paulo: LTr, 2002. 